\title{
Effect of immersion time in mouthwash on the flexural strength of polyethylene fiber-reinforced composite
}

\author{
Syazwani Akmal*, Widowati Siswomihardjo**, Siti Sunarintyas** $\bowtie$ \\ *Klinik Pergigian Kempas, Government Clinic, Persiaran Tanjung, Tampoi, 81200 Johor Bharu, Johor, Malaysia \\ **Department of Biomaterials, Faculty of Dentistry, Universitas Gadjah Mada, Yogyakarta, Indonesia \\ **JI Denta No 1 Sekip Utara, Yogyakarta, Indonesia; $₫$ correspondence: sunarintyassiti@ugm.ac.id
}

Submitted: 26 $6^{\text {th }}$ October 2018; Revised: 14 ${ }^{\text {th }}$ May 2019; Accepted: $2^{\text {st }}$ May 2019

\begin{abstract}
Fiber-reinforced composite (FRC) fixed dentures are exposed to various oral environments. One of the ways in maintaining good oral condition is by using mouthwash. Questions have been araised about the safety of prolonged use of mouthwash towards FRC. The aim of this study was to evaluate the effect of immersion time in mouthwash on the flexural strength of polyethylene FRC. The specimens used were polyethylene FRC (Construct, KerrLab, USA) and flowable composite resin (Master Flow Biodinamica, Brazil). Block shaped specimens (2x2x25 mm) was light cured $(n=12)$. Specimens were divided into threek groups of immersion: Group 1 (without immersion); Group 2 (24 hour immersion); Group 3 (48 hour immersion). The mouthwash used was Listerine Multi-Protect (Johnson \& Johnson, Indonesia) (21.6\% alcohol content). Flexure strength was measured by Universal Testing Machine. The results showed the average strength value (MPa) for Group 1 was $91.318 \pm 12.466$, Group 2 was $62.253 \pm 8.027$, and Group 3 was $55.033 \pm 3.373$. Statistical analysis (ANOVA) showed that immersion time in mouthwash influenced the flexural strength of polyethylene FRC $(p<0.05)$. $L_{0.05}$ showed there were significant differences of flexural strength between Group 1-Group 2, Group 1-Group 3 but not for Group 2-Group 3. In conclusion, the flexural strength of polyethylene FRC were decreased by the immersion time in mouthwash.
\end{abstract}

Keywords: flexural strength; immersion time; mouthwash; polyethylene fiber-reinforced composite

\section{INTRODUCTION}

Fiber-reinforced composite (FRC) is a combination of fibers and resin matrix. The fibers embedded in the matrix could be glass, polyethylene, carbon, or Kevlar. Polyethylene FRC in dental applications is very popular in recent years because of its strength and highly favorable mechanical properties compared to other fiber types. Polyethylene fibers possess unique mechanical properties in terms of high specific strength and stiffness. When compared with other reinforcing fibers, polyethylene fibers have a high elongation at break, leading to high values of work to break. Thus, polyethylene fibers have a high capability for using composite structures that requires excellent impact properties. ${ }^{1}$

When FRC materials used in dental applications such as crown and bridge restorations, the materials are exposed to the oral environment. Characteristics of the oral environment and the presence of degradation in composite resin material play an important role in maintaining the longevity and durability of dental composite resins restoration. The factors that can lead to the degradation of composite resins are the water, saliva, drinks, and foods. ${ }^{2}$

Effective plaque-control is essential for the maintenance of periodontal health and control of cariogenic activity. Mouthwash is a liquid solution that is commonly applied as a rinse regularly to enhance oral health, esthetics, and breath freshness. ${ }^{3}$ Mouthwashes is consider as one of the factors that can degrade composites resin restoration and their use has been increasing recently. ${ }^{4}$ Mouthwash contains various therapeutically active ingredients such as essential oils, chlorhexidine component, 
Majalah Kedokteran Gigi Indonesia. April 2020; 6(1): 39 - 47

ISSN 2460-0164 (print)

ISSN 2442-2576 (online)

fluoride, potassium nitrate, benzydamine and there is one ingredient that is commonly present in almost every mouthwash that is "alcohol". Alcohol is a good polymer chain solvent. High alcohol concentrations in mouthwash produce softening of the surfaces of resin materials and can degrade the mechanical properties and increase the wear of composite resins. $^{2,3}$

Solvent absorption causes deterioration in the physical and mechanical properties of composite resin restorations due to damage of the hydrolytic bond between the silane coupling agent and the filler particles as well as filler-matrix debonding or even hydrolytic degradation of the fillers. ${ }^{5,6}$ Mechanical properties such as flexural strength, tensile strength, modulus of elasticity and wear resistance of the composite resins may be negatively affected and lead to material failure. ${ }^{7}$ The aim of this research was to investigate whether the immersion time in mouthwash affected the flexural strength of polyethylene fiber-reinforced composite resin for restorative material.

\section{MATERIALS AND METHODS}

This research was an experimental laboratory study. It was conducted at two laboratories: Integratated Research Laboratory, Faculty of Dentistry and Material Laboratory of Engineering Faculty, Universitas Gadjah Mada, Yogyakarta, Indonesia. The ethical clearance certificate of the research obtained from the Ethics Committee of Dentistry Faculty, Universitas Gadjah Mada, with the number of certificate 00926/KKEP/FKG-UGM/EC/ 2017.

The preparation of the sample based on ISO 9917-2. Samples used in this study were rectangular polyethylene fiber-reinforced composite resins with the size of $(2 \times 2 \times 25) \mathrm{mm}$. The samples consisted of braided ultra-high molecular weight polyethylene (UHMWPE) fibers (Construct, KerrLab, USA) and flowable dental composite resin (Master Flow Biodinamica, Brazil). The mouthwash used understudy was Listerine ${ }^{\circledR}$ Multi Protect (Johnson\&Johnson, Indonesia), which contained $21.6 \%$ alcohol.

Three group test samples for the flexural strength test were prepared. Each group contained

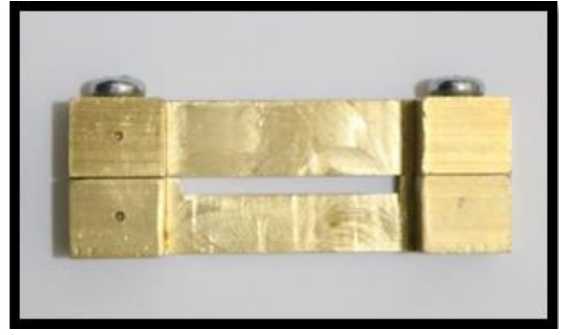

Figure 1. Brass mould

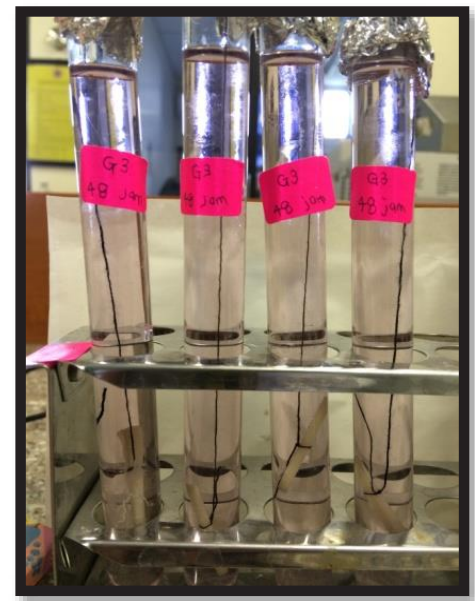

Figure 2. Treatment FRC samples in mouthwash

four samples. In line with ISO 10477:92, samples were prepared with the brass mold as in Figure 1. The polyethylene fibers were kept in desiccators for 24 hours to avoid its exposure to moisture from the atmosphere. The polyethylene fibers were cut into strips for $25 \mathrm{~mm}$ long to accommodate for the adaptation into the brass mold.

A small amount of flowable composite resin was injected into the brass mold. The polyethylene fibers were dipped using tweezers into the flowable composite resin. All parts of the polyethylene fibers must be covered with flowable composite resin material. At every corner of the mold was given a mark of $0.8 \mathrm{~mm}$ from the base of the mold. The flowable composite was injected into the mold until $0.8 \mathrm{~mm}$ mark was reached. Excess material was removed, and a transparent polyester matrix was placed before the second glass slide was placed on top of the mold with gentle pressure. A load of $500 \mathrm{~g}$ was placed and pressed to extrude the excess material and obtain uniform specimens.

Light polymerization was performed using visible light-curing unit (LED) for 20 seconds each. 
The tip diameter of the light-curing unit was $8 \mathrm{~mm}$. To light cure of a total length of $25 \mathrm{~mm}$, three times curing of $8 \mathrm{~mm}$ length and one time curing of $1 \mathrm{~mm}$ length was carried. For each time, the out. The part that was not being cured was covered by aluminum foil. After the polymerization completed, all samples were taken out from the mold. Any excess material was removed by gently grinding on both sides with silicon carbide paper.

Twelve test tubes with caps were prepared and grouped into three groups (Figure 2). A small hole was punched in each lids, and the required length of cotton thread glued to it. Each sample was tied at the end of the cotton thread. All twelve samples were randomly divided into three groups, as in Table 1.

The present study used a commersial mouthwash product of original Listerine $₫$ Multi Protect (Johnson\&Johnson, Indonesia), which contained $21.6 \%$ alcohol. The temperature of the moutwash immersion was maintained at $37{ }^{\circ} \mathrm{C}$ in the incubator. ${ }^{8}$ After the immersion duration completed, all samples were taken out using pincet.

Table 1. Sample groups

\begin{tabular}{cl}
\hline Group & \multicolumn{1}{c}{ Treatment } \\
\hline 1 & FRC without immersion in mouthwash \\
& (negative control group). \\
2 & FRC immersed in $20 \mathrm{~mL}$ mouthwash for a \\
& total of 24 hours immersion duration, which \\
& was equivalent to 4 years of 1-minute daily \\
& mouthwash use. \\
& FRC immersed in $20 \mathrm{~mL}$ mouthwash for a \\
& total of 48 hours immersion duration, which \\
& was equivalent to 8 years of 1-minute daily \\
& mouthwash use.
\end{tabular}

To conduct the flexural strength test, all the specimens must be stored in water at $37^{\circ} \mathrm{C}$ for 24 hours before the test (ISO 9917-2). After 24 hours, samples were taken out from distilled water, dried, and tested for flexural strength.

Flexural strength test was performed using Universal Testing Machine. The specimen lay on a support span, and the load was applied to the center by the loading nose producing three-point bending at a rate of $5 \mathrm{~mm} / \mathrm{min}$ and distance of 20 $\mathrm{mm}$ between the two spans following ISO 10477:92 (Figure 3).

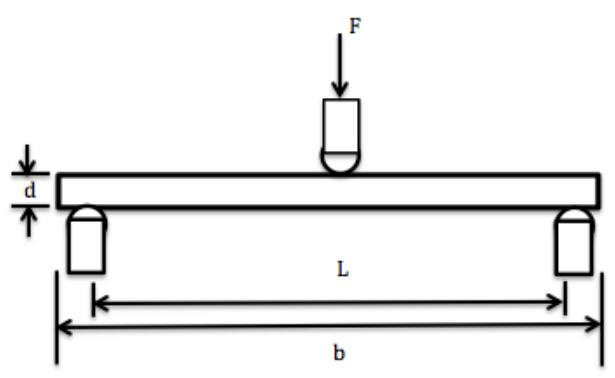

Figure 3. Schematic of three-point flexure test. ${ }^{9}$

The flexural strength test measured the maximum stress that it can resist before failure when subjected to bending load. Flexural strength value $(\sigma) \sigma) \sigma) \sigma$ ) was calculated using the following formula ${ }^{10}$ :

$$
\sigma=\frac{3 F L}{2 b d^{2}} \sigma=\frac{3 F L}{2 b d^{2}}
$$

Where:

$F$ : maximum load at fracture point $(\mathrm{N})$,

$L$ : distance between supports $(\mathrm{mm})$,

$b$ : specimen width $(\mathrm{mm})$

$d$ : specimen height $(\mathrm{mm})$

$\sigma \sigma \sigma \sigma$ : Flexural strength value, measured in Mega Pascals (MPa)

In determining the effect of immersion time in mouthwash on the flexural strength of the polyethylene FRC, the data were statistically analyzed using one-way analysis of variance (ANOVA) with $\alpha=0.05$ by SPSS version 20. Post hoc analysis using Tukey's LSD (Least Significance Different) was carried out after the ANOVA.

\section{RESULTS}

This study was conducted to determine the effect of immersion time in mouthwash on the flexural strength of polyethylene FRC. Research had been done on twelve rectangular specimens of polyethylene FRC. All specimens were prepared in the Integrated Research Laboratory of Faculty 
of Dentistry of Universitas Gadjah Mada. Flexural strength measurements were carried out by a 3-point universal testing machine (Pearson Panke Ltd, London) in Material Laboratory of Department of Mechanical and Industrial Engineering, Universitas Gadjah Mada, Indonesia. The results of the test were shown in Table 2.

Shapiro Wilk Test determined the normality of data for small samples (samples less than 100). The test was to determine the suitable statistical method to analyze the current data in detail; when the data belonged to a normal distribution, it was appropriate to use parametric tests. Levene's test was conducted to verify the homogeneity of the data.

Table 3 showed that the data in the variables were distributed normally because the values of Shapiro Wilk Test were not statistically significant $(p>0.05)$. When the significant level of Shapiro Wilk Test was above 0.05 ( $p>0.05)$, it indicated that the data were in normal distribution. This Levene's Test showed a significance of $p=0.216$ which means that these data are homogen $(p>0.05)$. To further verify the hypothesis, a parametric test was done on the current study by one-way ANOVA.

One-way ANOVA (Table 4) showed that the flexural strength values of polyethylene FRC immersed in various immersion time of mouthwash were significantly different among the groups $(p<0.05)$. Further $\mathrm{LSD}_{0.05}$ post hoc test (Table 5) showed there was a significant difference flexural strength value between Group 1 with Group 2 and also between Group 1 and Group 3, still, there was no significant difference between flexural strength value of Group 2 with Group 3.

Table 2. Mean value of flexural strength (Mpa)

\begin{tabular}{cc}
\hline Group & Mean \pm standard deviation \\
\hline 1 & $91.318 \pm 12.466$ \\
2 & $62.253 \pm 8.027$ \\
3 & $55.033 \pm 3.373$ \\
\hline
\end{tabular}

Table 3. Result of Shapiro-Wilk test

\begin{tabular}{cccc}
\hline \multirow{2}{*}{ Group } & \multicolumn{3}{c}{ Shapiro-Wilk test } \\
& Statistic & df & Sig. \\
\hline 1 & 0.908 & 4 & 0.469 \\
2 & 0.954 & 4 & 0.744 \\
3 & 0.957 & 4 & 0.761 \\
\hline
\end{tabular}

Table 4. Anova result of FRC in mouthwash

\begin{tabular}{lccc}
\hline & df & F & Sig. \\
\hline Between Groups & 2 & 19.148 & 0.001 \\
Within Groups & 9 & & \\
Total & 11 & & \\
\hline
\end{tabular}

Table 5. Results of LSD post hoc test

\begin{tabular}{cccl}
\hline $\begin{array}{c}(\mathrm{I}) \\
\text { Group }\end{array}$ & $\begin{array}{c}(\mathrm{J}) \\
\text { Group }\end{array}$ & $\begin{array}{c}\text { Mean difference } \\
(\mathrm{I}-\mathrm{J})\end{array}$ & Sig. \\
\hline 1 & 2 & $29.06500^{*}$ & 0.001 \\
& 3 & $36.28500^{*}$ & 0.000 \\
2 & 1 & $29.06500^{*}$ & 0.001 \\
& 3 & 7.22000 & 0.275 \\
3 & 1 & $36.28500^{*}$ & 0.00 \\
& 2 & -7.22000 & 0.275 \\
\hline
\end{tabular}

*The mean difference is significant at the 0.05 level. Group1 : without immersion in mouthwash Group2 : immersion time of $24 \mathrm{~h}$ in mouthwash Group3 : immersion time of $48 \mathrm{~h}$ in mouthwash

\section{DISCUSSION}

The properties and mechanics of fiber-reinforced composites are complex, and it is essential to anticipate the behavior and limitations of the fiber-reinforced composite. Features like strength and durability of dental composite resins are significantly influenced by the characteristics of the oral environment and the presence of degradation in composite restorations. Degradation occurs in areas that are unexposed to abrasion and compression due to the presence of chemical degradation. In this study, it is of interest to find out the effect of immersion time in mouthwash that contains alcohol on the flexural strength of the ultrahigh molecular weight polyethylene fiber-reinforced composite.

Immersion times duration of this research were adapted from the previous study, which analyzed the effect of mouthwash on surface hardness of dental ceramics. ${ }^{8}$ The immersion time on the previous study was designated for 24 and 96 hours, which was equivalent to 2 and 8 years of 2 minutes daily use, respectively. In this research, the immersion time of 24 and 48 hours was chosen regarding stimulating the 4 and 8 years of 1 minute daily use of mouthwash, respectively, considering the ideal length of time for rinsing was 30 seconds, twice a day. 
The results in Table 2 showed the flexural strength of polyethylene FRC samples after immersed in different immersion time of mouthwash showed statistical differences. Group 1 (0-hour immersion) revealed the highest flexural strength $(91.318 \pm 12.466 \mathrm{MPa}$ ) while Group 2 (24-hour immersion) and Group 3 (48-hour immersion) showed lower flexural strength values compared to Group 1 with $62.253 \pm 8.027 \mathrm{MPa}$ and 55.033 $\pm 3.373 \mathrm{MPa}$ respectively. The results indicated that the flexural strength of polyethylene FRC in Group 2 had been reduced by $31.83 \%$ after 24 -hour immersion in mouthwash. As for polyethylene FRC in Group 3, the flexural strength had been reduced by $39.73 \%$ after 48 -hour immersion in mouthwash. These data showed that the immersion time in mouthwash had reduced the flexural strength of polyethylene fiber-reinforced composite.

Fiber-matrix interfacial bond strength significantly affected the mechanical behavior of fiber-reinforced polymer (FRP) composite. This was probably because the polymer networks of the resin absorbed water and chemicals from the environment. This mechanism involved these two opposing processes: 1) the solvent (mouthwash) extract the unreacted components, mainly monomer, eventually resulting in shrinkage, loss of weight and reduction in mechanical properties; 2) solvent uptake leads to a swelling of the composite resin, and there would be an increase in pressure. This condition probably happened because the linear chains of the polymer disintegrated as the ethanol in mouthwash penetrated the polymeric network and caused the expansion of the polymer structure.

The alcohol present in mouthwash to causing a detrimental effect on the fiber-reinforced composite. This result was in agreement with the previous study findings, which showed alcohol presented in the mouthwash had been found to be one of the substances that had the solubility parameters within a range that caused the softening of restorative resins. ${ }^{11}$ This finding was following the previous research, which revealed that both bis-GMA and UDMA-based polymers were susceptible to chemical softening by ethanol. ${ }^{12}$ This softening effect was found to be directly related to the percentage of alcohol in the mouthwashes. ${ }^{13}$ It was appeared that the $21.6 \%$ ethanol content in the mouthwash used in this study, potentially affecting the mechanical properties of polyethylene FRC. Ethanol was known to cause softening of the resin composite surface by removing the polymer structure as the unreacted monomer, oligomers, and linear polymers ${ }^{14}$ or imparts an opener structure to the polymer, decreasing its physical properties and increasing wear characteristics. ${ }^{15}$

Previous studies confirmed the association of alcohol in mouthwash with the alterations in the physical-mechanical properties of resinbased composites. Results showed in vitro that a heat-treated resin composite gained significantly more weight when soaked in alcohol-containing mouthwashes than in alcohol-free mouthwashes. ${ }^{16}$ Aging in an ethanol and water mixture resulted in probable absorption of ethanol and water, resulting in penetration of the cross linked-matrix, weakening the resin, and decreasing the mechanical properties of resin composite material. ${ }^{17}$ This theory seemed to be demonstrated in the present study. The reduction in flexural strength of the polyethylene FRC samples in this study could be the result from the aging in mouthwash solution containing ethanol. Alteration of resin composite microstructure was caused by ethanol resulted from the removal of unreacted monomers, oligomers, and linear polymers from the structure of the polymer. Expansion of polymer structure took place when ethanol penetrated the polymeric network, allowing the unreacted monomers to be released and causing the breakup of the linear chains of the polymer.

Another mechanism in which release of substances from polymeric materials occurs was due to the presence of unbound monomers and additives in the polymer. Polymerization of the methacrylate monomers in fiber-reinforced composite resin caused a highly crosslinked structure. However, there was no total conversion during polymerization. Approximately 15-50\% of the methacrylic groups remained unreacted. Solvents eluted these unbound monomers and additives within the first hour after polymerization. ${ }^{18}$ 
Ferracane described that many polymer networks were considered to be mostly insoluble structures with relatively high chemical and thermal stability. ${ }^{19}$ However, these networks probably absorbed water and chemicals from the environment. In turn, the system released components to its surroundings. The phenomena of sorption and solubility served as precursors to a variety of chemical and physical processes that produce harmful effects on the structure and function of the polymeric material. These effects include volumetric changes such as swelling, physical changes such as plasticization and softening, and chemical changes such as oxidation and hydrolysis. These events might permanently alter the properties of the network, and the performance of the polymer might be compromised. Those explained why the flexural strength value of these samples in this current research that were immersed in mouthwash (Group 2 and Group 3) showed lower flexural strength value than samples that were not immersed in mouthwash (Group 1).

From this research, it was clear that the alcohol content in the mouthwash influenced the mechanical properties presented by polyethylene FRC. As an excellent dimetharylate solvent, alcohol might have swelled the polymeric matrixes of the resin in the FRC, thus increasing the number of unreacted monomers and oligomers that diffused out of materials. In either case, the ethanol and water mixture, being a better solvent for the composite, had a more exceptional ability to diffuse into the polymer matrix than did the water and was, therefore more tenaciously bound within the specimen. ${ }^{20}$ The present findings had demonstrated that immersion in mouthwash had resulted in lower flexural strength (Group 2 and Group 3) than those immersed in distilled water (Group 1).

Statistical results of the LSD post hoc test showed that there was no significant difference in the mean flexural strength value between Group 2 and Group 3. It was apparent from this research that the immersion in mouthwash decreased the flexural strength of polyethylene FRC. Still, the further decrease in flexural strength between two-immersion times under investigation was not significant statistically. It was assumed that even when considering longer immersion time, the reduction in flexural strength of the polyethylene FRC would not be significant statistically. The probable explanation of this result might be related to the incorporation of polyethylene fibers in the polymer matrix. This result supported the finding of previous research that confirmed the suitability of the fibers for reinforcing denture bases. ${ }^{21}$ They discovered that the incorporation of high-performance polyethylene fibers into acrylic denture base resin resulted in a significant reduction in water sorption. Those were because polyethylene fibers were hydrophobic, and replacing the hydrophilic resin with hydrophobic fibers produced in the high modulus fibers and the strength of the fiber-resin interface restrained the dimensional changes of the resin. That was indicating that degradation did not take place to such an extent that the mechanical properties of reinforced materials were affected.

According to Ferracane, it was a timebased process in which a degradation reaction in composite materials would undoubtedly require time to produce significant quantities of any byproduct, suggesting that elution studies needed to examine several time points. ${ }^{19} \mathrm{He}$ mentioned that the duration of exposure was an important determinant of what if any influenced a molecule may have on the material's polymer network. Previous research on the determination of the water uptake and strength characteristics of a nano filled resin-based composite supported this statement. ${ }^{22}$ It was described that the mechanical properties of resin-based composites were widely acknowledged to be influenced by the presence of water, and the water-induced degradation had been identified as a time-dependent process proportional to the degree of water sorption. The results from Group 2 and Group 3 indicated that polyethylene FRC produced lower flexural strength after being immersed in mouthwash. However, the immersion time in mouthwash under the current investigation had no significant influence on the flexural strength of polyethylene FRC. It was safe to say that, even considering daily use of mouthwash, the 
flexural strength of polyethylene FRC would not be significantly altered by the mouthwash.

There were, however, other possible explanations to describe the lower flexural strength presented by Group 2 and Group 3. In a previous study, it was found that polyethylene fibers did not produce higher flexural strength in either material than the unreinforced group, which may be attributed to poorly bonded fibers, thus creating the equivalent of voids. ${ }^{23}$ Detrimental hydrolytic effected and decreased the mechanical properties of reinforced resin were likely due to the improper impregnation that increased water sorption. In this case, the reinforced samples had many channels to help water penetration inside the fiber-reinforced composite samples, also to existence of interface between the glass fibers and the matrix, which considered as capillary tubes for the transport of water and penetrated inside the samples. The previous study explained there were three significant mechanisms of water sorption in fiberreinforced composites, which were: 1) Diffusion mechanism occurred inside the micro gaps between the chains of polymers; 2) Transport of water molecules mechanisms occurred through the microcracks which can appear in the matrix and; 3) Capillary transport mechanism which occurs in the gaps at fiber-matrix interface space. ${ }^{24}$ The results shown by Group 2 and Group 3 might have also been due to the poorly bonded fibers to the resin matrix. Immersion in mouthwash had affected somewhat the flexural strength of polyethylene FRC. In addition to that, Asmussen demonstrated the extent of polymerization of polymers that changed the properties of bis-GMA based polymers. ${ }^{11}$ It was known that there was no total conversion during polymerization. $\mathrm{He}$ also demonstrated that ethanol had been shown to exert a softening effect on bis-GMA based polymer, and this effect is more pronounced when resin polymerization is incomplete. Those things could explain the behavior of the samples that show lower flexural strength values after immersion in mouthwash.

The limitations of this study included the fact that the immersion procedures were conducted without time intervals, and the specimens were subjected to the mouthwash action continuously. In clinical application, the FRC materials did not expose continually to mouthwash solutions. The exposures towards mouthwash were intermittent, and the oral environment between exposure periods could elute chemical components like ethanol on the FRC. Then, the FRC would adsorb water molecules, which acted as a plasticizer to a lesser extent than ethanol. In other words, the harmful effects on the FRC might be less significant. However, in this research on the influence of immersion time in mouthwashes could represent several years of polyethylene FRC considering daily use of mouthwash and the alcohol content in mouthwash.

Clinically, the effects of mouthwash on materials were modified by many factors, which may not be replicated in an in vitro setting. Saliva diluted or buffered the mouth rinse, thus reducing the softening effect, and a coating of salivary pellicles might have a protective effect on the fiber-reinforced composite. ${ }^{25}$ The resistance to degradation in the oral environment played an essential role in the service life of the fiber-reinforced composite. Thus, even when obtained in vitro, results that increased the knowledge basis about sorption and solubility phenomena were crucial to predicting the behavior of fiber-reinforced composites when applied in the oral cavity.

It is important to bear in mind that intraoral conditions are more complex than those achieved in the laboratory. This in vitro study might not be able to represent the crown and bridge application of polyethylene FRC in the mouth because the load and direction of forces applied to teeth during masticatory functions are complex. In a natural dentition, maximal occlusal biting forces can increase to $900 \mathrm{~N}$ in the molar region. Still, chewing forces are significantly lower, and usually between $100 \mathrm{~N}$ and $300 \mathrm{~N}$. Also, maximal occlusal forces may be applied to teeth 3000 times per day. Therefore, although dynamic loading may be a closer simulation of the clinical conditions, none of the test methods used today is entirely able to simulate all the different movements of occlusion, including bruxism. ${ }^{26}$ However, this research finding was an 
important clue to the performance of composite in vivo. It suggested that the duration of exposure of polyethylene FRC in mouthwash immersion decreased the flexural strength of polyethylene FRC value. However, the decreasing amount was not significant for longer immersion duration. This research confirmed the safety and suitability of polyethylene FRC in dental applications.

\section{CONCLUSION}

The flexural strength of polyethylene fiber-reinforced composite under investigation was influenced by the immersion time in mouthwash.

\section{ACKNOWLEDGMENT}

The authors wish to thank the academic staff of the Faculty of Dentistry, Universitas Gadjah Mada, and Mechanical and Industrial Engineering Faculty of Engineering Universitas Gadjah Mada for their technical assistance and support throughout the research.

\section{REFERENCES}

1. Park R, Jang J: Performance improvement of carbon fiber/polyethylene fiber hybrid composites. Journal of Materials Science.1999; 34(12): 2903-2910.

2. de Moraed Porto IC, das Neves LE, de Souza CK, Parolia A, Barbosa dos Santos N. A Comparative Effect of Mouthwashes with Different Alcohol Concentrations on Surface Hardness, Sorption and Solubility of Composite Resins. Journal of Oral Health and Dental Management. 2014; 13(2): 502-506.

3. Craig RG, Powers JM. Restorative dental materials. 11th ed. St. Louis, United State of America: Mosby; 2002. 203-205.

4. Gagari E, Kabani S. Adverse effects of mouthwash use. Oral Surgery, Oral Medicine, Oral Pathology, Oral Radiology, and Endodontology. 1995; 80(4): 432-439. doi: 10.1016/S1079-2104(05)80337-3

5. Soderholm KM, Roberts MJ. Influence of water exposure on the tensile strength of composites. J Dent Res.1990; 69(12): 1812-1816. doi: $10.1177 / 00220345900690120501$
6. Sarrett DC, Coletti DP, Peluso AR. The effects of alcoholic beverages on composite wear. Dental Materials. 2000; 16(1): 62-67. doi: 10.1016/S0109-5641(99)00088-3

7. Sideridou ID, Karabela MM, Vouvoudi EC, Papanastasiou GE. Sorption and desorption parameters of water or ethanol in lightcured dental dimethacrylate resins. Journal of Applied Polymer Science. 2007; 107(1): 463-475. doi: 10.1002/app.27094

8. Jafari K, Hekmatfar $\mathrm{S}$ and Badakhsh S. The effect of mouthwashes on surface hardness of dental ceramics. J. Dent. Biomater. 2014; 1(1): 23-26.

9. Mallick PKK. Fiber-reinforced composites: Materials, manufacturing, and design. United States: Boca Raton, Florida, U.S.A. 2007; 2.

10. Sakaguchi RL, Powers JM. Craig's restorative dental materials, 13th ed. Philadelphia: Elsevier/Mosby. 2012; 85. 164.

11. Asmussen E. Softening of BISGMAbased polymers by ethanol and by organic acids of plaque. European Journal of Oral Sciences. 1984; 92(3): 257-261. doi: 10.1111/j.1600-0722.1984.tb00889.x

12. Kao EC. Influence of food-simulating solvents on resin composites and glass-ionomer restorative cement. Dent Mater.1989; 5(3): 201-208. doi: 10.1016/0109-5641(89)90014-6

13. Penugonda B, Settembrini L, Scherer W, Hittleman E, Strassler H. Alcohol-containing mouthwashes: effect on composite hardness. J Clin Dent. 1994; 5(2): 60-62.

14. Asmussen E, Peutzfeldt A. Influence of pulse-delay curing on softening of polymer structures. Journal of Dental Research. 2001; 80(6): 1570-1573. doi: $10.1177 / 00220345010800061801$

15. McKinney JE, Wu W. Chemical softening and wear of dental composites. Journal of Dental Research.1985; 64(11): 1326-1331. doi: $10.1177 / 00220345850640111601$

16. Weiner R, Millstein P, Hoang E, Marshall D. The effect of alcoholic and non-alcoholic 
mouthwashes on heat-treated composite resin. Operative Dentistry. 1997; 22(6): 249-253.

17. Ferracane $\mathrm{JL}$, Berge HX. Fracture toughness of experimental dental composites aged in ethanol. J Dent Res. 1995; 74(7): 1418-1423. doi: $10.1177 / 00220345950740071501$

18. Goldberg M. In vitro and in vivo studies on the toxicity of dental resin components: a review. Clin Oral Investig. 2008; 12(1): 1-8. doi: $10.1007 / \mathrm{s} 00784-007-0162-8$

19. Ferracane JL. Hygroscopic and hydrolytic effects in dental polymer networks. Dent Mater. 2006; 22(3): 211-222. doi: 10.1016/j.dental.2005.05.005.

20. Ferracane JL, Condon JR. Rate of elution of leachable components from composite. Dental Materials. 1990; 6(4): 282-287. doi: 10.1016/S0109-5641(05)80012-0

21. Chow TW, Cheng YY, Ladizesky NH. Polyethylene fiber reinforced poly (methyl methacrylate) - water sorption and dimensional changes during immersion. Journal of Dentistry. 1993; 21(6): 367-372. doi: 10.1016/0300-5712(93)90014-H

22. Curtis AR, Shortall AC, Marquis PM, Palin WM. Water uptake and strength characteristics of a nanofilled resin-based composite. J Dent. 2008; 36(3): 186-193. doi: 10.1016/j.jdent.2007.11.015
23. Kamble VD, Parkhedkar RD, Mowade TK. The effect of different fiber reinforcements on flexural strength of provisional restorative resins: an in-vitro study. J Adv Prosthodont. 2012; 4(1): 1-6. doi: 10.4047/jap.2012.4.1.1

24. Munoz E, Garcia-Manrique JA. Water absorption behavior and its effect on the mechanical properties of flax Fiber-reinforced Bioepoxy composites. International Journal of Polymer Science. 2015(6); 1-10. doi: 10.1155/2015/390275

25. Gurgan S, Onen A, Koprulu H. In vitro effects of alcohol-containing and alcoholfree mouthrinses on microhardness of some restorative materials. J Oral Rehabil. 1997; 24(3): 244-246.

26. Valittu PK, Könönen M. Biomechanical aspects and material properties. In: Karlsson $\mathrm{S}$, Nilner $\mathrm{K}$ and Dahl B (eds). A textbook of Fixed Prosthodontics. The Scandinavian Approach. Stockholm: Föorlagshuset Gothia AB; 2000. 116-130. 